\title{
Yunus Emre Düşüncesinde Hayır ve Şer
}

\author{
Goodness and Evil in Yunus Emre Thought
}

\author{
Mehmet Kenan ŞAHİN 1
}

\author{
Araștırma Makalesi / Research Article \\ Geliş Tarihi / Received: 22.12.2021 \\ Kabul Tarihi / Accepted: 25.12.2021 \\ Doi: 10.48146/odusobiad.1039927
}

Atıf / Citation: Şahin, M. K., (2021). "Yunus Emre Düşüncesinde Hayır ve Şer” ODÜSOBİAD “Yunus Emre ve Türkçe Özel Sayısı” 1-8, Doi: 10.48146/odusobiad.1039927

\begin{abstract}
Öz
Yunus Emre Düşüncesinde Hayır ve Şer isimli çalıșma, Yunus Emre'nin Divan ve Risâletü'n-Nushiyye adlı eserlerinde yer alan hayır ve şer algısını konu etmektedir. Yunus'un şiirlerinde kötülük/şer sorunu tartışılırken bir yandan kâdir-i mutlak bir yaratıcı ve onun sınırsız kudreti dile getirilmiș, diğer yandan O'nun sonsuz merhameti üzerinde durulmuştur. Yunus Emre bu dünyada yapılan haksızlıkların karşılıksız kalmayacağı ve âdil olan yaratıcı tarafından cezalandırılacağı görüșündedir. Yunus'a göre kötülük ya da șer sorunu yaratıcı ile yaratılan arasındaki ilişkinin doğru anlaşılamamasından kaynaklanmaktadır. Yunus Emre insanın yaşadığı nesnel âlemde kötülüklerin varlığını inkâr etmemekle birlikte kötülüklerin bir hikmet çerçevesinde gerçekleștiği, ancak insanın bu hikmeti her zaman kavrayamayabileceği düşüncesindedir. 0 insanın bu hikmetlerin tamamını kavramaya çalışmasını abes olarak değerlendirmiștir. Önemli olan kötülüklere rağmen yaratıcı ile bağları koparmamak, O’na güvenmektir.
\end{abstract}

Anahtar Kelimeler: Yunus Emre, Şer, Kötülük, Tanrı

\begin{abstract}
Our study, titled "Goodness and Evil in Yunus Emre Thought ", deals with the perception of good and evil in Yunus Emre's works titled Divan and Risaletü'n Nushiyye. While discussing the problem of evil/evil in Yunus's poems, an omnipotent creator and his unlimited power are mentioned on the one hand, and his infinite mercy is emphasized on the other. It has been stated that injustices will not go unrequited and will be punished by the just creator. According to Yunus, the problem of evil or evil stems from the wrong understanding of the relationship between the creator and the creature. Yunus Emre does not deny the existence of evil in the objective world in which man lives. According to Yunus, evil has a wisdom, and this wisdom cannot always be fully grasped by people. Man is out of place in knowing the wisdom behind the Creator's creation of evil. The important thing is not to break the ties with the creator despite the evil, to trust him.
\end{abstract}

Keywords: Yunus Emre, Good, Evil, God

İnsanın gündelik yaşamı teknolojik yeniliklerle her geçen gün daha konforlu hale gelmektedir. Ancak insanlık açışından aynı gelişimden bahsetmek mümkün değildir. Bugün olup bitenlere baktığımızda beklenenin aksine dünyanın geçmișe nazaran daha güvenli ve sorunsuz hale geldiğini söylemek mümkün olmamaktadır. Dünyada gelir seviyesinde meydana gelen dengesizlik her geçen gün derinleşmekte, insanlık bireysel ve bencil bir yaşama sürüklenmekte ve evrensel ahlâkî değerlerden uzaklaşılmaktadır. İnsanlar adına günümüzde kişisel sorunların yanı sıra aile ve toplumla yaşanan çatıșmalar artmakta, bununla birlikte uzlașma imkânı gün be gün daha uzak hale gelmektedir. Ahlâkî değerlerden yoksunluk, ben merkezli yașam tarzı, kendi çıkarını hedefleme, başkasına hayat hakkı tanımama günümüz insanının genel karakteristik özellikleri arasına girmektedir. Halbuki insan sosyal bir varlıktır. Tarihi süreç boyunca insanların güvenliklerini sağlamak ve ihtiyaçlarını karşılamak adına daima bir arada yaşadıkları bilinmektedir. Savaşların, doğal afetlerin, açlık ve sefaletin yer aldığı bir dünyayla bireysel şekilde baş etmenin mümkün olmadığı, insanların varlıklarını devam ettirebilmeleri için yardımlaşma ve dayanışma içinde bulunma zorunlulukları tüm bu süreçler incelendiğinde net olarak ortaya çıkmaktadır. Tarih söz konusu

${ }^{1}$ Prof. Dr., Ordu Üniversitesi, ORDU, e-mail:, mkenansahin@hotmail.com, ORCID ID: 0000-0002-4184-2509 
yardımlaşma ve dayanışmanın zayıfladığı ve düzeni sağlamanın zorlaştığı dönemlerde düşünceleriyle toplumları sağduyuya çağıran, umut meşalesi yakan, birlik ve beraberliği yeniden sağlamaya çalışan önemli isimlere şahit olmuştur.

XIII. yüzyılda Anadolu Selçuklu Devleti Haçlı Seferlerine maruz kalmış, aynı dönemlerde Moğol istilasıyla karşılaştığında güçsüzleşmiş ve dağılma sürecine girmiştir. Bu dönemde halkın içinden çıkan, toplumu bilinçlendiren ve sağduyuya çağıran, güçlü ve ümit var olmayı öğütleyen şahsiyetlerden biri, belki de döneminin en tanınan ve geniş kitlelere hitap ettiği bilinen Yunus Emre (1240-1320) olmuştur. Bu çalışmada Yunus Emre'nin insan anlayışının bir parçasını oluşturan hayır ve şer konusundaki düşüncelerinin derlemesi yapılacaktır. Yunus'u daha iyi anlayabilmek için öncelikle onun yaşadığı dönemin siyasî, sosyal ve kültürel durumu kısaca açıklanmalıdır.

\section{Yunus Emre'nin Yaşadığı Dönem; Siyasî, Sosyal ve Kültürel Durum}

İbn Haldun'un deyişiyle insan yaşadığı coğrafyanın çocuğudur. Toplumda derin izler bırakmış ve tüm insanlığa mâl olmuş, ilim ve irfan sahibi kimseler de yaşadıkları coğrafyanın atmosferinden etkilenmiştir. Öyle ki Yunus Emre'nin yaşadığı XIII. (1240-1320) asır, Anadolu Selçuklu Devleti'nin hüküm sürdüğü, M.1243 yılında Moğollarla giriștikleri Kösedağ Savaşılyla bölgede siyasî gücünü yetirdiği, sonuçta Moğolların Sivas'ı ve Kayseri'yi istila ettiği bir dönemdir. Moğol istilası sonucu Anadolu'da devlet otoritesi ortadan kalkmış, birçok insan Moğolların zulmüne mâruz kalmıştır. Devletin başında bulunan II. Giyâseddin Keyhüsrev Anadolu'yu terk etmiş ve coğrafya büyük ölçüde Moğolların egemenliğine girmiştir. 1246 yılında II. Gıyâseddin Keyhüsrev'in ölümüyle birlikte Anadolu'da Türkmen beylikleri arasında kıyasıya mücadele başlamıştır. 1289 yılında Türkmen Beyliklerinden biri olan Osmanoğulları Beyliği Yunus'un yaşadığı Eskişehir ve çevresine hâkim olana kadar bölge insanı birçok zulme ve haksızlığa uğramıştır. Bu çekişmeli ortam söz konusu coğrafyada yaşayan insanlar üzerinde ağır baskı oluşturmuş, halk bezgin bir hale gelmiş ve düzen konusunda umutlarını kaybetmiştir. Anadolu insanı bitkin düşmüş, açlık ve kıtlıkla yüz yüze gelmiştir. (Uzunçarşıll, 1988, s. 1-37)

İște Yunus Emre halkı canından bezdiren ve yorgun düșüren böylesine zor koșulların bulunduğu bir dönemde yaşamış ve Yüce Allah'ın "Allah'ın rahmetinden umut kesmeyiniz" (Zümer 39:53) meâlindeki ilahî beyanından ilham alarak gelecek için ümitvar olmayı ilke edinmiştir. Onun şiirleri inanç ve sabırla her türlü sıkıntıların üstesinde gelinebileceği düşüncesi üzerine kaleme alınmıştır. Bu dönemde Yunus Emre kendisine yaşadığı toplumu dinî, insanî ve ahlâkî değerler temelinde bir arada tutmayı misyon edinmiştir. (Karakoç, 2009, s. 67). Nitekim Yunus Emre bir şiirinde de zorluklar karşısında dağılmamayı ve geleceğe sabırlı adımlarla yürümeyi şu ifadelerle dile getirmiştir:

Sabır gözetsin devlet dileyenler,

"Bil ki Hak, sabredenlerle beraber"

Sabırla hâlin güzel olur gayet,

Gelir sabredene Hak'tan inayet (Risâletü'n Nushiyye,2013, 88.)

\section{Yunus Emre Düşüncesinde Hayır ve Şer}

Şer hayrın karşıtı olarak bilinir. Sözlükte 'kötülük, çirkin, zararlı, kötülüğe meyletmek' gibi anlamlara gelir. Terim olarak "Kimsenin hoșlanmayıp yüz çevirdiği zararlı ve kötü şey; zararlı şeylerin yayılması, bir şeyin kendi tabiatıyla örtüşmemesi” anlamını ifade eder. (Topaloğlu ve Çelebi, 2017, s. 291) Dinî literatürde ise Yüce Allah'ın yasakladığı ve işlenmesi durumunda ceza gerektiren inançlar ve eylemler için kullanılmıştır. Dolayısıyla da lügat anlamı itibariye hayrın zıddı olan kötülük, çirkinlik, habislik gibi anlamlara gelen şer ya da kabîh sözcügü dinen Allah'ın emri ve insanın fitratıyla bağdaşmayan kötü ve zararlı şeyleri ifade etmektedir.

Kur’ân-ı Kerîm'de şer kelimesi otuza yakın âyette geçmektedir. Yüce Allah'ın “Sana gelen iyilik Allah'tandır. Başına gelen kötülük ise nefsindendir. Seni insanlara elçi gönderdik; şahit olarak da Allah yeter." (Nisâ 4:79) meâlindeki ilâhî beyanında iyiliğin Allah'tan kötülüğün ise insanın kendisinden kaynaklandı̆̆ı haber verilmiştir. Allah'ın kullarını nimet vererek sınadığı gibi korku, açlık, mal ve can kaybıyla da imtihan ettiği de (Bakara 2:155-156; Âl-i İmrân 3:180; Enbiyâ 21:35) bildirilmiştir. Yine başka bir âyette ise nelerin iyilik 
nelerin kötülük getireceğinin insanlarca tamamıyla bilinemeyeceği, kişinin sevmediği bir şeyin iyi, sevdiği şeyin de kötü olabileceği haber verilmiştir. (Bakara 2:216). Diğer bir âyette ise zerre kadar hayır işleyen bir kimsenin mükâfatını alacağı, zerre kadar kötülük işleyen bir kimsenin de cezasını göreceği bildirilmiştir. (Zilzâl 99:7-8). Benzer şekilde insanların en kötüsünün aklını kullanmayan, gerçeği dinlemek ve söylemek istemeyen, bu sebeple Allah'ın lânetine ve gazabına uğrayan inkârcıların olduğu zikredilmiștir. (Mâide 5:60; Enfâl 8:22, 55; Beyyine 98:6). Yunus Emre söz konusu âyetleri bütüncül bir şekilde değerlendirmiș, şiirlerinde Allah'ın hayra yönelmeyi ve kötülükten uzak durmayı emrettiği üzerinde ehemmiyetle durmuştur.

Günümüz kelâm ve felsefe kitaplarında şer kavramı doğal, ahlakî ve metafizik olmak üzere üç çeşit olarak ele alınmaktadır. Bu minvalde Yunus Emre'nin hayır ve şer anlayışını kötülüğün doğal, ahlâkî ve metafizik türlerini dikkate alarak incelemek; hayrın ve șerrin mâhiyeti, kaynağı ve insanla ilişkisi üzerindeki düşüncesini anlamak adına daha isabetlidir.

\section{Hayrın ve Şerrin Kaza ve Kaderle İlişskisi}

Şer ya da kötülük meselesi esasında felsefe tarihinde birçok düşünür tarafından tartışılan en kadim felsefî sorunlardan biridir. Aynı şekilde İslâm kelâm geleneğinde bu sorun birçok düşünür tarafından dikkate alınmış ve teorilerle açıklanmaya çalışılmıştır.

Tarih boyunca insanoğlu yaşamını olumsuz olarak etkileyen acı verici sel, deprem, yangın, su baskınları, açlık ve kıtlık gibi afetlerle karşılaşmıştır. İnsan hayatına doğrudan etki eden bu felaketlerin kaynağı daima sorgulamıștır. Hayrın ve șerrin kaynağının ne olduğu, her şeye gücü yeten kâdir-i mutlak ve iyi olan Tanrı'nın bunlara nasıl izin verdiği ya da gücü yettiği halde neden önlemediği soruları felsefî ve teolojik tartıșmaların odağını olușturmuștur. İslâm kelâm geleneğinde bu sorun kazâ ve kader meselesine bağlı olarak hüsün-kubuh kavramları çerçevesinde tartışılmıştır. İslâm düşünürleri Yüce Allah'ın iyilik ve güzellikleri irade ettiğini ve yarattığını kabul etmekle birlikte, kötülük ve çirkinlikleri dileyip dilemediği, kötülüklerin yaratıcısı olup olmadığı meselesinde görüș ayrılığı yaşamıștır. Görüldüğü üzere hayır ve șerrin mutlak olup olmadığı ve kaynağı kadim felsefede olduğu gibi İslam felsefesinde ve kelâm ilmine de konu olmuş, böylece mesele felsefe ve kelam geleneğinin temel teolojik soruları arasına girmiştir.

Yunus Emre tarafından da irdelenen konuda onun görüșüne göre șerrin ya da kötülüğün felsefî ve kelâmî bir problem olarak tartışılmasında yaratan ile yaratılan; diğer bir deyişle her şeye kâdir olan bir tanrı anlayışı ile insan arasındaki ilişkinin doğru anlaşılmamasının payı büyüktür. Öyle ki sonsuz, mutlak kudrete ve iradeye sahip kâdir-i mutlak bir yaratıcı ve sonlu, sınırlı kudret ve iradeye sahip mahlûkât arasındaki ilişki temelde doğru anlaşılmadığında şer ya da kötülük olgusu yanlış düşüncelere kapı aralayabilmektedir. Yunus Emre bir şiirinde Yüce Allah'ın sınırsız kudret ve iradesini vurgulayarak, evrende hiçbir şeyin onun emri ve iradesi dışında gerçekleşemeyeceğini şu ifadelerle dile getirmektedir:

\section{'Kimin kâfir idüp kimin müselmân}

Anı kimse itmez illâ ol eyler.' (Yunus Emre Divanı, 2005, s. 95)

Yine başka bir şiirinde aynı düşünce şu şekilde ifade edilmiştir:

'Bile idüm Hazret'de ol bi- klyâs kudretde

Ne şerikum varıdı ne kimseyle yâr idüm.' (Yunus Emre Divanı, 2005, s. 223)

Yunus'un bu ifadelerinden yola çıkarak hayrın ve șerrin kaynağının Allah olduğu ve insanın fiillerinde hiçbir bir sorumluluğunun bulunmadığı sonucuna varılabilir mi?

Yunus'u anlamak için her şeyden önce kazâ ve kaderin mâhiyetine yönelik düşüncesine bakılmalıdır. Sözlükte kazâ 'yerine getirme, hüküm, bir işi bitirmek, yaratmak, ulaştırmak, ölmek, ameli sağlam yapmak, infâz etmek, bildirmek, takdir etmek, gerektirmek, ihtiyacı gidermek, borcu ödemek, tamamlamak' anlamlarında kullanılmaktadır. (İbn Manzûr, t.y., 3665-3667) Kader ise 'takdir, hüküm, gücü yetmek, planlamak, ölçü ile yapmak, bir şeyin şeklini ve niteliğini belirlemek, hikmete göre yapmak' anlamlarına gelmektedir. (Râzî, 1980, s.464- 465) Terim anlamında ise kavramlar kelâm ekolleri tarafindan daha çok kendi düşünce sistemlerine uygun bir şekilde tanımlanmıștır. Örneğin İmam Mâturîdî (ö. 331/944) kazâyı; "Allah'ın nesne ve olayları kendi mahiyeti çerçevesinde yaratması ve her şeyin yaratılışına uygun düşecek pozisyonda bulunmasını sağlamasıdır." şeklinde tanımlamıştır. Mâturîdî’ye göre bütün yaratıkları yoktan var eden Allah hikmet ve ilim sahibidir. O'nun yaratmasının da bu hikmete göre cereyan etmesi ilâhî 
adaletinin bir gereğidir. Kader ise Mâturîdî düşünceye göre yaratılan her şeyin meydana geleceği zaman ve mekânı, hak veya bâtıl oluş vasfını, doğuracağı ödül ve cezayı belirlemektir. Buna karşın Eş'arîlere göre kazâ Allah'ın varlıkları mâhiyetine göre ezelde irâde etmesi, kader ise 0'nun varlıkları murad ettiği belirli bir şekle ve özel bir ölçüye göre yaratmasıdır. (Nesefî, 2003, s. 306-315)Buradan anlaşllan Eş'arîler, Mâturîdîlerin kazâ dediğini kader, onların kader dediğini de kazâ olarak tanımlamıştır. Böylece Eş'arî âlimlere göre kader yaratmaktan ibaret kalmaktadır ve Allah’ın fiilî sıfatlarından birini ifade etmektedir. Mâturîdîlere göre ise kader ilim sıfatına râcidir ve Allah'ın ezelî sıfatlarından biridir. Yine Eş'arî âlimlere göre kazâ kavramı Allah'ın irade sıfatıyla ilgilidir ve zâtî sıfatlarındandır. Mâturîdîlere göre ise Allah'ın yaratmasından ibarettir Bu durumda kazâ onların nazarında fiilî bir sıfattır.

Kısaca Eş'arî âlimlere göre kader hâdis, kazâ ise kadîm bir sıfattır. Mâturîdîlerde ise tam tersi bir algı söz konusudur. (Bâcûrî, 2002, s. 188-189). İki ekolün aynı kavramlara farklı anlamlar yüklemeleri insan fiilleri ve hürriyeti meselesinde farklı düşünmelerine yol açmıştır.

Kazâ ve kadere verilen anlam insan fillerinin yönü üzerinde önemli etkiye sahiptir. Her şeyin önceden belirlendiği ve insanın belirlenen bu yazgıya göre bir yaşam sürdüğü şeklindeki düşünce kelâm tarihinde Cebriyye mezhebine nispet edilmiştir. Cehmiyye'nin kurucusu Cehm b. Safvan insanın kader karşısında rüzgarın önünde bir yaprak misali savrulduğunu ve fiillerinde hiçbir sorumluluğunun bulunmadığını savunmuştur. $\mathrm{Bu}$ düşünce erken dönem kelâm âlimlerinden Hasan Basrî ve Mu'tezile'nin kurucuları tarafından şiddetle eleştirilmiş ve reddedilmiştir. Daha sonraki teorilerin hepsine göre Kur'ân-ı Kerîm'de bu konuda yer alan âyetler bir bütünlük içerisinde değerlendirildiğinde ortaya çıkan tablo insanın iradî bir varlık olduğunu ve yaptıklarından sorumlu tutulacağını göstermektedir. Kur'ân'da kader sözcügünün geçtiği tek âyette insanın fiillerinin ona sorumluluk bırakmayacak şekilde belirlendiğine dair bir ima bulunmamaktadır. Âyette kelime Allah'ın ilim sıfatıyla ilişkilendirilmekte, ilim sıfatının bir tezahürü olarak O’nun evrene koyduğu ölçüden bahsetmektedir.

Yunus'un şiirlerine bakıldığında onun kadere ilişkin görüşlerini yansıtan birçok ifade bulunmaktadır. Örneğin Bir şiirinde kaderden bahsederken şu ifadeleri kullanmıştır:

'Yunus imdi gam yime n'idem ne kllam dime

Gelür kişi başına ezelde ne yazıla' (Yunus Emre Divanı, 2005, s. 474)

Burada açıç̧a Yunus'un Allah'ın ilminde ezelde her şeyin yazılı olduğunu kabul ettiği görülmektedir. Buradan hareketle onun cebrî bir anlayışta olduğunu söylemek zorlama olacaktır. Zira olayların Allah'ın ezelî ilminde yazılı olmasının cebri gerektirmediği o dönemde neredeyse tüm âlimler tarafından dile getirilmiştir. Burada anlatmak istediği ezelde yazılan her şeyin insanın başına geleceğidir, ancak bu insanın yazgısının ona hiç pay bırakmayacak șekilde belirlendiği anlamına gelmez. Yunus burada Yüce Allah'ın ilim sıfatına işaret etmektedir. Anlatmak istediği Allah'ın ilminin geçmiş, şimdi ve geleceği kapsadığı; insanın kendi iradesi ve isteği ile gerçekleştirdiği tüm fiillerini Allah'ın ezelde bildiği ve bu fiillerin onun bilgisine uygun olarak meydana geldiğidir. Zira Yunus șiirlerinde insanları iyi huylar edinmeye ve hayra davet ederek bu konudaki tavrını belli etmiștir.

'Bize bizden ulular inen eyi hûlular

Ol eyü 'amellüler haber böyle dir gider.'

"Bize bizden ulular inan iyi huylular, 0 iyi amelliler haber böyle der gider."

'Kesgil harâmdan elün kesgil gaybetden dilün

Azrâîl el'irmedin bu dükkânı dir gider.' (Yunus Emre Divanı, 2005, s. 21)

"Elini haramdan, dilini glybetten kesgil, Azrail el erdirmeden bu dükkâna der gider."

Bu satırlarda Yunus insanlardan kendilerini düzeltmelerini ve ölüm gelmeden davranışlarına çekidüzen vermelerini istemektedir. Bu talebin mutlak cebir düşüncesine sahip birinden çıkması mümkün değildir. Kaldı Yunus bir şiirinde de şu ifadelerle insanı salih amel işlemeye yöneltmektedir:

Özünü bilmek sana farz oldu gel,

Amel eyle seninle gider amel. 
Biraktın akli sen seni unuttun,

Kin ve grybet nedir onu unuttun.(Risâletü’n Nushiyye,2013,127)

\section{Hayır ve Şerrin Hikmetle İlişkisi}

Literal olarak 'bilgelik, doğruluk, bilim ve ince marifet' anlamlarına gelen hikmet (Çağrıcı, 2018, s. 40) terim anlamında 'bilgelik, gizli sebep, Tanrı'nın insanlarca anlaşılmayan amacı, ilahî sırların ve gerçeklerin bilgisi, varlıkların varoluş amaçlarının kavranması, sebeplerle sonuçları arasındaki iliş̧ilerde ilahî iradenin rolünün keșfedilmesi' anlamlarında kullanılmıștır. (Kara, 1998, s. 518-519) Nesnel âlemde şerrin/kötülüğün varlığını kabul eden Yunus şerrin varlığını ilahî hikmet ile açıklamaktadır. Yunus'a göre bize şer gibi görünen şeylerin dahi bir hikmeti vardır. Bu hikmeti kavramada insan yetersiz kalabilir. Zira insan sınırlı bilgiye ve imkânlara sahip olması bakımından her olayın özünü idrak etmede eksiktir. İlk anda iyi olduğu düşünülen her şey zamanla kötüye dönme imkânını içinde barındırır. Aynı imkân bunun tersi durumlar için de geçerlidir. Nitekim Yüce Allah "Savaş, hoşunuza gitmediği hâlde, size farz kılındı. Olur ki, bir şey sizin için hayırlı iken, siz onu hoş görmezsiniz. Yine olur ki, bir şey sizin için kötü iken, siz onu seversiniz. Allah bilir, siz bilmezsiniz."(Bakara 2:216) buyurmaktadır. Varlıkları ve olayları algılayıșta sınırlı bilgiye sahip bir varlık olan insan Allah'ın sınırsız bilgisine güvenmeli ve ona teslim olmalıdır. Yunus Emre ilâhî hikmet karşısında şaşkınlığını 'Allah sana irmez elüm hikmetine kaldım tana' (Yunus Emre Divanı, 2005, s. 7) dizeleriyle dile getirmiştir.

Yunus Emre hikmeti manevî boyutu olan bir bilgi olarak da görmektedir.

'Ilm ile hikmet ile kimse irmez bu sirra

Bu bir acayib sırdur ilme kitaba sığmaz.' (Yunus Emre Divanı, 2005, s. 110)

O başa gelen sıkıntılar ve kötülükler karşısında insanları aceleciliği bir kenara bırakıp kavrayamadıkları bir hikmetin olabileceğini düşünerek sağduyulu ve sabırlı olmaya davet etmektedir.

'Hazeran dürlü hikmetler katunda söylenür ise

Şekavet penbesin hergiz kulağundan çıkarmazsın.' (Yunus Emre Divanı, 2005, s. 235)

Yunus Emre dünyada çekilen kötülüklerin kişiye ahiret hayatında yarar sağlayacağı ve çektiği sıkıntıların karşılı̆̆ında insanın mükâfat kazanacağı düşüncesindedir.

'Dünya cefasın almak sonucu vefaymış

Cefayı virbenin seni satın aldum ben.' (Yunus Emre Divanı, 2005, s. 280/7)

Yunus dünyada kötülüğün varlığını kabul etmekle birlikte nesnelerin tabiatında kötülüğün var olduğu fikrini reddeder. Ona göre şer ârızîdir. Allah her şeyi iyi olarak yaratmıştır. Özünde her şey iyidir, eksiklik ve kusur insandandır. Eksiklikten münezzeh olan tek varlık ise Allah'tır.

'Yunus eksikliğini Çalabına arz eyle

Anın keremi çoktur, sen ettiğini ol etmez.' (Yunus Emre Divanı, 2005, s. 117/10)

\section{Hayır ve Şer'in Nefisle İlişskisi}

İnsan akıl ve irade sahibi bir varlık olarak üstün meziyetlere sahip bir yaratılışa sahip olmakla birlikte, kötülüğü ișlemeye ve meşru olmayan arzu ve isteklerinin peșinde gitmeye de meyyal bir tabiata sahiptir. Kur'ân-ı Kerîm'de Allah'ın “Nefse ve onu düzgün bir biçimde şekillendirip ona kötülük duygusunu ve takvasını (kötülükten sakınma yeteneğini) ilham edene and olsun ki, nefsini arındıran kurtuluşa ermiștir." (Şems, 91:79) meâlindeki ilahî beyanından anlaşıldığı gibi, insan, yaratılışında hem iyiliğe hem de kötülüğe meyyal bir yaratılışa sahiptir. İmam Mâturîdî'nin ifadesiyle:

"Allah insanları sorumluluk hissedecek șekilde yaratmıştır. Bu sorumluluğun temeli olacak şekilde onları iyiyi kötüden ayırmasını bilen temyiz sahibi varlıklar kılmış, akli idraklerine kötü davranışı çirkin, iyi davranışı da güzel göstermiş, yine onların zihnî kapasitelerini çirkini güzele tercih etmeyi, yergiye lâyık olan övülmeye değer bulunana üstün tutmayı kabul edilmez bir davranış olarak yerleştirmiştir. Bu sebepledir ki Allah insanların yapılarına yerleştirilen özelliklere ve kendilerine lütfedilen hasletlere paralel olarak bir davranışı diğerine 
tercih etmeye çağırmış ve bunun dışındakilere meyletmeyi bu yapıdaki bilinçli bir varlığın aklen benimseyemeyeceği kadar çirkin göstermiştir." (Mâturîdî, 2002, s. 284-285)

Yunus'a göre de insan nefis sahibi bir varlıktır. Onda bulunan duygu ve davranışlar yaratılışında oluşmuştur. İnsanın özü hava, su, ateş ve toprak unsurundan oluşmaktadır. Yunus'a göre insanda su ile gelen hisler, safa, seha ve kavuşma lütfudur. Ateş ile gelenler, şehvet, kibir, tama ve hasettir. Hava ile gelenler ise yalancılık, riya, acelecilik ve nefestir. Can ile gelenler ise izzet, birlik, haya ve edeptir. Yunus'un ifadesi ile:

Toprakla geldi bize dört nitelik:

Sabır, hoş huy, tevekkül ve yücelik.

Suyla beraber geldi dört türlü hâl;

Temizlik, cömertlik, lütuf ve visal.

Rüzgârla beraber geldi dört heves;

Yalan, riya, sabırsizlik ve nefes.

Ateşle geldi dört türlü felâket;

Şebvet, kibir, açözlülük ve haset.

Canla birlikte geldi dört özellik;

Utanma, ahlâk, üstünlük ve birlik. (Risâletü'n Nushiyye,2013, 20-21)

Yunus'a göre insan nefsinde iyiye ve kötüye yönelme konusunda sürekli savaş içindedir. İradî eylemlerinde insana düşen görev sürekli hakka ve doğru olana yönelmektir. Nefsin arzularına kapılmamak ve nefis ile savaşmak gerekir. (Yunus Emre Divanı, 2005, s. 201/10,11)

'Işk kadehinden içüp nefs dileğinden geçüp

Hak yolına er gibi turmayan aşık mıdur?' (Yunus Emre Divanı, 36.)

'Uram yıkam nefs evini oda yana hirsu heva

El götürem şimden girü nefsile savaş eyleyem.' (Yunus Emre Divanı, 197)

Yunus Emere insanın ziyanı kendi elleriyle yaptığını ise şu ifadelerle dile getirmiştir:

Kendi ziyanından kendisi kaçar,

Şer tohumunu çorak yere saçar.

Yaptı̆̆ her iş kendisine ziyan,

Var mıdır kendisine böyle kıyan? (Risâletü'n Nushiyye,2013, 91)

Öyle anlaşılıyor ki Yunus insanda bir iradenin varlığına kabul etmektedir. Yunus'a göre insan, iradesini nefsin istekleri ve arzuları doğrultusunda değil de doğru olana yönelerek kullanması gerekir.

'Nefsinün varlığını 'akl-ı külle ulaşdur

Varlıgun yoga degşür cevher ol olma muhas.' (Yunus Emre Divanı, 119.)

\section{Sonuç}


Yunus Emre'nin şiirleri incelendiğinde yer yer hayır ve şer kavramlarını kullandığı görülmekle birlikte felsefî ya da kelâmî manada kötülük sorununu ele alıp tartıştığı da söylenemez. Yunus evrende şerrin varlığını kabul etmektedir. Ancak Yunus'a göre evrende şerrin varlığının bir hikmeti vardır. Bu hikmeti insanoğlu kavrayamayabilir. İnsan, hikmetini kavramakta âciz kaldığı bu gibi durumlara takılarak Allah'a inanmaktan ve ona dost olmaktan geri durmamalıdır. Yunus'a göre insan Cebriyye'de olduğu gibi iradesi elinden alınmış pasif bir varlık değildir. Yunus'un Divan ve Risâletü'n-nushiyye adlı eserleri birlikte değerlendirildiğinde onun imana büyük önem verdiği, insanın nefsini dizginleyerek manevî yönünü geliştirebileceğine; şerden de uzaklaşarak hayra yönelebileceğine inandığı ve bu düşüncelerini sıklıkla şiirlerinde konu ettiği görülmektedir. 0 kötülüğün kendi başına bir gerçekliğinin olduğunu düşünmez. Kötülüğü ortaya çıkaran kimi faktörlerden söz etmiştir. Yunus'a göre nefis, kötü kişiler ve kötü çevre insanı olumsuz etkileyen ve kötü fiillere sürükleyen başlıca unsurdur. Nesnel âlemde insanın karşllaştığı ve kötü olarak gördüğü doğal kötülükler ise ilk bakıșta olumsuz gibi gözükse de esasında sonuçları itibariyle insanı daha da olgunlaştırabilecek ve onlar adına iyiliğe dönüşebilecek şeylerdir. Bu tür şerrin hayra dönüşmesi mümkündür.

\section{Extended Abstract}

Yunus Emre is the subject of the perception of good and evil in his works. In his works reflecting his world of thought, he gives reference to God, his attributes and names, his power and majesty, his justice and the wisdom in his actions, evident in its characteristics. For this reason, in this study, we tried to make sense of his religious thought by focusing on some of his views that are especially related to the issue of good and evil. In Yunus's poems, the problem of evil is mentioned in the axis of God's justice and mercy, although perhaps not philosophically or theologically deep. When looked at, Yunus is of the opinion that the injustices committed by people against each other in this world will not go unrequited and will definitely be punished by the just creator. Again, according to him, the problem of evil or evil stems from the inability to understand the relationship between the creator and the creature correctly. Yunus Emre does not deny the existence of evil in the objective world in which human beings live. On the contrary, it states that after the existence of evils is known, evils occur within the framework of a purpose. However, Yunus is of the opinion that man may not always grasp this divine purpose. In this case, what should be called the efforts made by man in order to understand the purpose of the existence of some evils? In response to such a question, he considered it futile for a person to try to grasp all of these wisdoms. According to him, the most correct thing for a person to do in the face of evil is to not break the ties with the creator and to be devoted to God, despite the existence of evil and touching people.

As we mentioned before, when Yunus Emre's poems are examined carefully, it is seen that he sometimes uses the concepts of good and evil. However, it is also difficult to say that he dealt with the problem of evil from the eyes of a philosopher or theologian and made solutions. While explaining this subject, it starts with acknowledging the existence of evil in the universe. As we have mentioned before, according to Yunus, the existence of evil is known in the universe, and the existence of evil has its own wisdom. According to Yunus, this hidden wisdom and purpose that lies in the ontology of evil is outside the scope that people can understand and encompass. Yunus's suggestion here is that his attitude towards evil, which is an issue for which man cannot understand the wisdom, should not stop people from believing in God and being a friend to him by being stuck in such situations in which he is incapable. According to Yunus, man should not be seen as a passive being who has no authority and power, whose will has been completely taken away, as the Jabriyya sect claims. It is understood that Yunus gives advice with many examples of this attitude in his works. When the issue of good and evil in Yunus's religious thought is evaluated together with his other views, it is seen that he attaches great importance to faith and that man can develop his spiritual side by restraining his soul; It is seen that he believes that he can turn to good by turning away from evil, and he often mentions these thoughts in his poems. He does not think that evil has a reality of its own without any outside influence. According to him, it is necessary to mention some factors that bring out evil. As an example of these factors, nafs, bad people and bad environment affect people negatively and stand out as the main factors that lead people to commit some bad actions. The natural evils that people encounter in the objective world and that they see as bad at first glance may seem negative at first glance, but in fact, they are things that can make people more mature and turn into goodness on their behalf. It is possible for such evil to turn into good. As a result, although a person is immediately worried about something bad that has happened to him, he will not really distinguish a category as evil in his 
mind when he realizes that this situation has many benefits and benefits for him later on. For example, a person knows that when he is sick, he should consult a doctor and take medicine. In this case, it can also be considered that the doctor prescribes needle therapy to the person concerned to improve his disease. Getting an injection is a scary and painful thing for a person. However, even though the person knows that he will suffer and be afraid, he does not stop being an injection and still applies to a specialist to be injected. As in this example, if the person had known beforehand the benefits that he would later get from some things that seemed to be bad, he probably would not have considered it bad. For this reason, when a person evaluates each of the evils from this perspective, he also points out the basic starting point in Yunus's thought. In our opinion, although people know some things very well, they will be able to realize how little they actually know about certain things by just looking at their appearance, after Yunus' examples.

\section{Kaynakça}

Bacûrî, İ. M. (2002). Şerhu Cevhereti't-Tevhîd. Kahire: Yy.

Çağrıcı, M. (2018). İslam Düşüncesinde Ahlak. İstanbul: Dem Yayınları.

İbn Manzûr, E. C. M. (T.Y.). Lisânu'l-'Arab. Cilt V. Kahire: Dâru'l-Me'Ârif.

Kara, M. (1998). "Hikmet”, Türkiye Diyanet Vakfı İslam Ansiklopedisi. Cilt Xvı. İstanbul: Türkiye Diyanet Vakfı Yayınları.

Mâturîdî, E. (2002). Kitâbu't-Tevhîd. (Çev. Bekir Topaloğlu). İstanbul: İSAM Yayınları.

Nesefî, E. M. (2003). Tabsıratü'l-Edille Fî Usûli'd-Dîn, (Thk. Hüseyin Atay Ve Şaban Ali Düzgün). Cilt Il. Ankara: D.İ.B. Yayınları.

Râzî, M. (1980). Muhtâru's- Sıhah: Mu'Cemu'r-Râzî. İstanbul: Çağrı Yayınları.

Tatcı, M. (2005). Yunus Emre Divanı İnceleme. İstanbul: Meb Yayınları.

Topaloğlu Ve Çelebi, B. Ve İ. (2017). Kelâm Terimleri Sözlüğü. İstanbul: İsam Yayınları.

Uzunçarşıll, İ. H. (1988). Osmanlı Tarihi, Cilt I. Ankara: Türk Tarih Kurumu Yayınları.

Yunus Emre, (2005). Divân Ve Risâletü'n-Nushiyye. (Yay. Haz. Mustafa Tatcı). İstanbul: Sahaflar Kitap Sarayı. 